Pacific Journal of Mathematics

SIMPLE QUADRATURES IN THE COMPLEX PLANE 


\section{SIMPLE QUADRATURES IN THE COMPLEX PLANE}

\section{PHILIP J. DAVIS}

Given a class $S$ of functions that are Riemann integrable on $[0,1]$. A quadrature formula $\int_{0}^{1} f(x) d x=\sum_{i=1}^{\infty} a_{i} f\left(x_{\imath}\right)$ is called a simple quadrature for $S$ if the $x_{i}$ are distinct and if both the $a_{i}$ and the $x_{\imath}$ are fixed and independent of the particular function of $S$ selected. It is known that if $S$ is too large, for example if $S=C[0,1]$, a simple quadrature cannot exist. On the other hand, if $S$ is sufficiently restricted, for example the class of all polynomials, then simple quadratures exist.

The present paper investigates further the existence of simple quadratures. It is proved among other things that if $S$ is the class of analytic functions that are regular in the closure of an ellipse with foci at \pm 1 , a simple quadrature exists for the weighted integral $\int_{-1}^{+1}\left(1-x^{2}\right)^{1 / 2} f(x) d x$ provided we allow the abscissas $x_{\imath}$ to take on complex values.

1. Simple Quadratures. In [3], the author studied the following question. Suppose that there has been given a fairly extensive class $S$ of real functions that are Riemann integrable on $[0,1]$. Does there exist a quadrature formula of the form

$$
\int_{0}^{1} f(x) d x=\sum_{i=1}^{\infty} a_{i} f\left(x_{i}\right)
$$

which is valid for all functions of the class $S$ ? The abscissas $x_{i}$ are assumed distinct, and both the weights $\alpha_{i}$ and the abscissas $x_{i}$ are fixed and independent of the particular function of $S$ selected. A quadrature of the form (1) was called a simple quadrature to contrast it with quadratures of the form

$$
\int_{0}^{1} f(x) d x=\lim _{n \rightarrow \infty} \sum_{i=1}^{n} a_{i n} f\left(x_{i n}\right)
$$

which allow more freedom than (1) and have accordingly been more frequently investigated. See, e.g., Szegö [9], Chap. 15.

In [3], we found, broadly speaking, that if $S$ is fairly small, simple quadratures exist, while if $S$ has too many functions in it, simple quadratures do not exist. Thus, for instance, there exists a simple quadratures for the class of all polynomials (of uncounded degree), while there cannot exist a simple quadrature for the class of continuous functions. See also Davis [7], Chap. 14, where this question is treated in the framework of weak* convergence.

Received April 25, 1964. This work was supported by the Office of Naval Research Contract Nonr 562 (36). 
An interesting intermediate class of functions that possesses a simple quadrature is the class $B$ of entire functions that are finite Fourier Transforms i.e., the class of functions $f(z)$ that have a representation of the form

$$
f(z)=\int_{-\sigma}^{\sigma} e^{i z t} \varphi(t) d t, \varphi(t) \varepsilon L[-\sigma, \sigma], \sigma \text { fixed. }
$$

In the communication literature, $B$ is known as the class of bandlimited functions. It is known, see, e.g. Boas [1] p. 220, that an $f(z)$ in $B$ can be represented by means of the cardinal series

$$
f(z)=\sum_{n=-\infty}^{\infty}(-1)^{n} f\left(\frac{n \pi}{\sigma}\right) \frac{\sin \sigma z}{\sigma z-n \pi}
$$

which is uniformly convergent in any bounded set in the complex $z$-plane. Hence, integrating term by term, we find

$$
\int_{0}^{1} f(x) d x=\sum_{n=-\infty}^{\infty} a_{n} f\left(x_{n}\right)
$$

where

$$
x_{n}=\frac{n \pi}{\sigma} \text { and } a_{n}=(-1)_{u} \int_{0}^{1} \frac{\sin \sigma x}{\sigma x-n \pi} d x .
$$

A similar argument shows that "simple" representations can be found for $B$ for all the usual linear functionals of numerical analysis such as derivatives, etc.

Interesting necessary and sufficient conditions for $S$ to allow a simple quadrature have not yet been determined. In the present paper, therefore, we shall investigate these matters further, considering certain integrals of analytic functions and allowing the abscissas to take on complex values. With this freedom, we shall show that simple quadratures exist for double integrals of analytic functions, for certain single integrals of analytic functions, and for certain inner product integrals associated with Hilbert Spaces of analytic functions.

2. Simple quadratures with complex abscissas. Our work is based upon a device whose use in complex variable theory goes back at least as far as Pompeiu [8], p. 165.

Lemma. Let $B$ be a bounded region in the complex plane. Then we can find a sequence of circles $C_{n}:\left|z-z_{n}\right|<r_{n}, n=1,2, \cdots$ such that

(1) each $C_{n}$ is contained in $B$

(2) the circles $C_{n}$ are nonoverlapping 
(3) the circles $C_{n}$ exhaust the area of $B$ :

$$
\sum_{n=1}^{\infty} \pi r_{n}^{2}=\text { area of } B
$$

Another way of putting (7) is that

$$
\operatorname{meas}\left(B-\bigcup_{n=1}^{\infty} C_{n}\right)=0 \text {. }
$$

Such a sequence of circles will be called a complete packing of $B$.

Proofs of this lemma are easily given. The reader is referred to the recent paper of $O$. Wesler [12] where a proof will be found. Wesler also gives a simple geometrical proof, utilizing the Borel-Cantelli lemma, of the interesting theorem, apparently due to S. Mergelyan, that the sum of the circumferences of the circles in a complete packing is infinite: $\sum_{n=1}^{\infty} r_{n}=\infty$.

The existence of complete packings is not restricted to packings by circles or to two dimensions.

Lemma. Let $C$ designate the circle $\left|z-z_{0}\right|<r$. If $f(z)$ is regular in $\bar{C}$, then

$$
\iint_{\sigma} f(z) d x d y=\pi r^{2} f\left(z_{0}\right)
$$

In this lemma, as in what follows, we have not attempted to put the most general conditions on $f(z)$. The above conditions are sufficient.

THEOREM. Let $B$ be a bounded region of the complex plane and let the circles $C_{n}:\left|z-z_{n}\right|<r_{n}(n=1,2, \cdots)$ constitute a complete packing of $B$. Then, if $f(z)$ is regular in $B$ and continuous in $\bar{B}$,

$$
\iint_{B} f(z) d x d y=\pi \sum_{n=1}^{\infty} r_{n}^{2} f\left(z_{n}\right) \text {. }
$$

Proof. In view of $\left(7^{\prime}\right)$,

$$
\iint_{B} f(z) d x d y=\sum_{u=1}^{\infty} \iint_{\sigma_{n}} f(z) d x d y
$$

An application of (8) now yields (9).

Notice that (9) gives us a simple quadrature that is valid for double integrals of analytic functions. There are infinitely many such simple quadrature formulas, each one corresponding to a different complete packing of the region $B$. Note also that in view of (7) and the boundedness of the sequence $\left\{f\left(z_{n}\right)\right\}$, the series in (9) converges absolutely. But in view of the divergence of $\sum_{n=1}^{\infty} r_{n}$, the convergence 
in (9) cannot be too rapid, and serious numerical applications are more than likely excluded.

The special selection of $B$ as the unit circle leads to the following corollary.

COROLlaRY. Let $C_{n}:\left|z-z_{n}\right|<r_{n}(n=1,2, \cdots)$ be a complete packing of the unit circle. Then, if $f(z)$ is regular in $C$ and continuous in $\bar{C}$,

$$
f(0)=\sum_{n=1}^{\infty} r_{n}^{2} f\left(z_{n}\right)
$$

Formula (11) may be regarded as a "simple" representation of the functional $L(f)=f(0)$ in terms of point functionals.

If we select $f(z)=1 /(w-z)$, then (10) leads to

$$
\frac{1}{w}=\sum_{n=1}^{\infty} \frac{r_{n}^{2}}{w-z_{n}} .
$$

This is Wolff's example of a convergent series of fractions that can be continued analytically into the region of the apparent poles! (Wolff [13]). Choosing $f(z)=z e^{z w}$ leads to $0=\sum_{k=1}^{\infty} \boldsymbol{r}_{k}^{2} z_{k} e^{z_{k} w}$, which is an absolutely convergent, nontrivial representation of 0 as a sum of exponentials. This should be contrasted with the more familiar Dirichlet series where this sort of behavior does not occur.

There is an amusing consequence of this method. As anyone knows (who has played with his change on a bar), it is not possible to find a complete packing of a circle by a finite number of circles other than the trivial identity packing. Proofs are easy to devise, but from our present point of view, this fact emerges as a consequence of interpolation by polynomials in the complex plane! For, suppose that $C_{k}$ : $\left|z-z_{k}\right|<r_{k}, k=1,2, \cdots, n$ were a complete packing of the unit circle. Then, as in (11),

$$
f(0)=\sum_{k=1}^{n} r_{k}^{2} f\left(z_{k}\right),
$$

and this must certainly be true for all polynomials $f$. If $z_{1}, \cdots, z_{n}$ are distinct from 0 , let $f(z)$ be that polynomial which vanishes at $z_{1}, \cdots, z_{n}$ and for which $f(0)=1$. This leads to the contradiction $1=0$. If one of the $z_{n}$, say $z_{1}$, is 0 let $f(z)$ be that polynomial that vanishes at $z_{2}, \cdots, z_{n}$, and for which $f(0)=1$. Then, $r_{1}^{2}=1$, the trivial case.

Formula (9) can be generalized as follows: Let $C_{k}:\left|z-z_{k}\right|<r_{k}$ be a complete packing of $B$. Then, if $f(z)$ and $g(z)$ are regular in $B$ 
and continuous in $\bar{B}$,

$$
\begin{aligned}
& \frac{1}{\pi} \iint_{B} f(z) \overline{g(z)} d x d y=\sum_{k=1}^{\infty} r_{k}^{2} f\left(z_{k}\right) \overline{g\left(z_{k}\right)} \\
& \quad+\frac{1}{2} \sum_{k=1}^{\infty} r_{k}^{4} f^{\prime}\left(z_{k}\right) \overline{g^{\prime}\left(z_{k}\right)}+\frac{1}{3(2 !)^{2}} \sum_{k=1}^{\infty} r_{k}^{6} f^{\prime \prime}\left(z_{k}\right) \overline{g^{\prime \prime}\left(z_{k}\right)} \\
& \quad+\frac{1}{4(3 !)^{2}} \sum_{k=1}^{\infty} r_{k}^{8} f^{\prime \prime \prime}\left(z_{k}\right) \overline{g^{\prime \prime \prime}\left(z_{k}\right)}+\cdots
\end{aligned}
$$

Proof. We have,

$$
f(z)=\sum_{m=0}^{\infty} \frac{f^{(m)}\left(z_{k}\right)\left(z-z_{k}\right)^{m}}{m !}, \quad \overline{g(z)}=\sum_{m=0}^{\infty} \frac{\overline{g^{(m)}\left(z_{k}\right)}\left(\overline{\left.z-z_{k}\right)^{m}}\right.}{m !},
$$

uniformly and absolutely convergent in the closure of $C_{h}$. Now, in view of the fact that

$$
\iint_{\sigma_{k}}\left(z-z_{k}\right)^{m}\left(\overline{\left.z-z_{k}\right)^{n}} d x d y=\frac{\pi}{m+1} r_{k}^{2 m+2} \delta_{m n},\right.
$$

we obtain from term by term integration,

$$
\begin{aligned}
& \frac{1}{\pi} \iint_{\sigma_{k}} f(z) \overline{g(z)} d x d y=r_{k}^{2} f\left(z_{k}\right) \overline{g\left(z_{k}\right)}+\frac{1}{2} r_{k}^{4} f^{\prime}\left(z_{k}\right) \overline{g^{\prime}\left(z_{k}\right)} \\
& \quad+\frac{r_{k}^{6}}{3(2 !)^{2}} f^{\prime \prime}\left(z_{k}\right) \overline{g^{\prime \prime}\left(z_{k}\right)}+\frac{r_{k}^{8}}{4(3 !)^{2}} f^{\prime \prime \prime}\left(z_{k}\right) \overline{g^{\prime \prime \prime}\left(z_{k}\right)}+\cdots
\end{aligned}
$$

3. The use of triangles. Another type of "simple" interpolation formula can be obtained by employing a triangle.

THEOREM. Let $T$ be a triangle whose vertices are at $w_{1}, w_{2}, w_{3}$ and whose area is $A$. Let $C_{n}:\left|z-z_{n}\right|<r_{n}$ be a complete packing of $T$. Then, if $f^{\prime \prime}(z)$ is regular in $\bar{T}$,

$$
\begin{aligned}
& \frac{f\left(w_{1}\right)}{\left(w_{1}-w_{2}\right)\left(w_{1}-w_{3}\right)}+\frac{f\left(w_{2}\right)}{\left(w_{2}-w_{1}\right)\left(w_{2}-w_{3}\right)} \\
& \quad+\frac{f\left(w_{3}\right)}{\left(w_{3}-w_{1}\right)\left(w_{3}-w_{2}\right)}=\frac{\pi}{2 A} \sum_{k=1}^{\infty} r_{k}^{2} f^{\prime \prime}\left(z_{k}\right) .
\end{aligned}
$$

Proof. Under the above conditions on $f$, we have the identity

$$
\begin{aligned}
& \frac{1}{2 A} \iint_{T} f^{\prime \prime}(z) d x d y=\frac{f\left(w_{1}\right)}{\left(w_{1}-w_{2}\right)\left(w_{1}-w_{3}\right)} \\
& \quad+\frac{f\left(w_{2}\right)}{\left(w_{2}-w_{1}\right)\left(w_{2}-w_{3}\right)}+\frac{f\left(w_{3}\right)}{\left(w_{3}-w_{1}\right)\left(w_{3}-w_{2}\right)}
\end{aligned}
$$


See Davis [6].

Now write $\iint_{T} f^{\prime \prime}(z) d x d y=\sum_{k=1}^{\infty} \iint_{\sigma_{k}} f^{\prime \prime}(z) d x d y$ and proceed as before.

4. The use of ellipses. When a weighted (real) integral of an analytic function can be shown to be equal to the double integral of its analytic continuation, then complete packings may be employed to produce a simple quadrature.

Let $B$ be selected to be an ellipse. The ellipse will be normalized as follows. $\varepsilon_{\rho},(\rho>1)$, will designate the ellipse whose foci are at $z=$ \pm 1 and whose semi-axes are respectively

$$
a=\frac{1}{2}\left(\rho+\rho^{-1}\right), \quad b=\frac{1}{2}\left(\rho-\rho^{-1}\right) .
$$

THEOREM. Let $C_{n}:\left|z-z_{n}\right|<r_{n}(n=1,2, \cdots)$ be a complete packing of the ellipse $\varepsilon_{\rho}$. If $f(z)$ is regular in the closure $\varepsilon_{\rho}$, then

$$
\int_{-1}^{+1}\left(1-x^{2}\right)^{1 / 2} f(x) d x=2 \pi\left(\rho^{2}-\rho^{-2}\right)^{-1} \sum_{n=1}^{\infty} r_{n}^{2} f\left(z_{n}\right) .
$$

Proof. We shall show that for all $f(z)$ regular in the closure of $\varepsilon_{\rho}$, we have the identity

$$
\iint_{\varepsilon_{\rho}} f(z) d x d y=\frac{1}{2}\left(\rho^{2}-\rho^{-2}\right) \int_{-1}^{+1}\left(1-x^{2}\right)^{1 / 2} f(x) d x .
$$

The quadrature formula (18) will then follow by writing

$$
\iint_{\varepsilon_{\rho}} f(z) d x d y=\sum_{n=1}^{\infty} \iint_{\sigma_{n}} f(z) d x d y .
$$

To show (19), introduce the Tschebyscheff polynomials of the 2nd kind

$$
U_{n}(z)=\left(1-z^{2}\right)^{-1 / 2} \sin [(n+1) \arccos z],(n=0,1, \cdots) .
$$

These polynomials are doubly orthogonal. We have, first of all, the real orthogonality

$$
\int_{-1}^{+1}(2 / \pi)^{1 / 2} U_{m}(x)(2 / \pi)^{1 / 2} U_{n}(x)\left(1-x^{2}\right)^{1 / 2} d x=\delta_{m, n} .
$$

But, if $c_{n, \rho}$ are the normalizing constants defined by

$$
c_{n, \rho}=2\left(\frac{n+1}{\pi}\right)^{1 / 2}\left(\rho^{2 n+2}-\rho^{-2 n-2}\right)^{-1 / 2},
$$




$$
p_{n}^{*}(z)=c_{n, \rho} U_{n}(z),
$$

then we also have the complex orthogonality

$$
\iint_{\varepsilon_{\rho}} p_{m}^{*}(z) \overline{p_{m}^{*}(z)} d x d y=\delta_{m n} .
$$

If $f(z)$ is regular in the closure of $\varepsilon_{\rho}$, then the complex Fourier expansion

$$
\begin{aligned}
f(z) & =\sum_{n=0}^{\infty}\left(\iint_{\varepsilon_{\rho}} f(z) \overline{p_{n}^{*}(z)} d x d y\right) p_{n}^{*}(z) \\
& =\sum_{n=0}^{\infty} c_{n, \rho}^{2}\left(\iint_{\varepsilon_{\rho}} f(z) \overline{U_{n}(z)} d x d y\right) U_{n}(z)
\end{aligned}
$$

converges uniformly and absolutely in closed subregions of $\varepsilon_{\rho}$. But the real Fourier expansion of $f(x)$

$$
f(x)=\sum_{n=0}^{\infty} \frac{2}{\pi}\left(\int_{-1}^{+1} f(x) U_{n}(x)\left(1-x^{2}\right)^{1 / 2} d x\right) U_{n}(x)
$$

also converges uniformly in $[-1,1]$. Hence, by the uniqueness of the Fourier coefficients, it must follow that

$$
\frac{2}{\pi} \int_{-1}^{+1} f(x) U_{n}(x)\left(1-x^{2}\right)^{1 / 2} d x=c_{n, \rho}^{2} \iint_{\varepsilon_{\rho}} f(z) \overline{U_{n}(z)} d x d y \quad n=0,1, \cdots
$$

Selecting $n=0$, and observing that $U_{0}(x)=1$, we obtain (19) from (28) and (23).

As an example of an expansion of type (18), write $f(x)=e^{w x}$. Then, (see, e.g. Watson [10], p. 79)

$$
\int_{-1}^{+1}\left(1-x^{2}\right)^{1 / 2} e^{w x} d x=\frac{\pi I_{1}(w)}{w}
$$

where

$$
I_{1}(w)=\frac{1}{2} w+\frac{1}{2 !}\left(\frac{1}{2} w\right)^{3}+\frac{1}{3 !}\left(\frac{1}{2} w\right)^{5}+\cdots
$$

is the modified Bessel function of the first order. Hence, if $\left|z-z_{n}\right|<$ $r_{n}, n=1,2, \cdots$ is a complete packing of $\varepsilon_{\rho}$, we have, for all $w$,

$$
\frac{I_{1}(w)}{w}=2\left(\rho^{2}-\rho^{-2}\right)^{-1} \sum_{n=1}^{\infty} r_{n}^{2} e^{z_{n} w} .
$$

Some further identities that relate to the Tschebyscheff polynomials $U_{n}(z)$ should be noted. Writing $f(z) U_{n}(z)$ for $f(z)$ in (19), we obtain

$$
\frac{4}{\pi}\left(\rho^{2}-\rho^{-2}\right)^{-1} \iint_{\varepsilon_{\rho}} f(z) U_{n}(z) d x d y=\frac{2}{\pi} \int_{-1}^{1}\left(1-x^{2}\right)^{1 / 2} f(x) U_{n}(x) d x
$$


Hence, from (28), and then from (20),

$$
\begin{aligned}
\iint_{\varepsilon_{\rho}} f(z) U_{n}(z) d x d y & =\frac{\pi c_{n, \rho}^{2}}{4}\left(\rho^{2}-\rho^{-2}\right) \iint_{\varepsilon_{\rho}} f(z) \overline{U_{n}(z)} d x d y \\
& =\pi \sum_{k=1}^{\infty} r_{k}^{2} f\left(z_{k}\right) U_{n}\left(z_{k}\right) .
\end{aligned}
$$

The particular selection of $f(z)=U_{m}(z)$ in (31) yields

$$
\begin{gathered}
\iint_{\varepsilon_{\rho}} U_{m}(z) U_{n}(z) d x d y=\frac{\pi c_{n, \rho}^{2}}{4}\left(\rho^{2}-\rho^{-2}\right) \iint_{\varepsilon_{\rho}} U_{m}(z) \overline{U_{n}(z)} d x d y \\
=\pi \sum_{k=1}^{\infty} r_{k}^{2} U_{m}\left(z_{k}\right) U_{n}\left(z_{k}\right)=\frac{\pi}{4}\left(\rho^{2}-\rho^{-2}\right) \delta_{m n} .
\end{gathered}
$$

The first term leads to a complex, but not Hermitian, orthogonality of the polynomials $U_{m}(z)$, while the $3 \mathrm{rd}$ is a point-wise orthogonality.

As a sideline, an inequality for analytic functions can be obtained from (19).

THEOREM. Let $f(z)$ be analytic in the circle $C_{r}:|z| \leqq r, r>1$. Let $f$ be real on the real axis and satisfy

$$
\operatorname{Re} f(z) \geqq 0, \quad z \in C_{r} \text {. }
$$

Then,

$$
\frac{r}{\sqrt{r^{2}-1}} f(0) \geqq \frac{2}{\pi} \int_{-1}^{+1}\left(1-x^{2}\right)^{1 / 2} f(x) \geqq \frac{\sqrt{r^{2}-1}}{r} f(0) .
$$

Proof. The circle $C_{r}$ contains the ellipse $\varepsilon_{\rho}$ where $r=(1 / 2)\left(\rho+\rho^{-1}\right)$, and the ellipse, in turn, contains the circle $C_{s}:|z| \leqq s$, where $s=$ $(1 / 2)\left(\rho-\rho^{-1}\right)=\sqrt{r^{2}-1}$. Now,

$$
\begin{aligned}
\pi r^{2} f(0) & =\iint_{\sigma_{r}} f(z) d x d y=\iint_{\sigma_{r}} \operatorname{Re} f(z) d x d y \geqq \iint_{\varepsilon_{\rho}} \operatorname{Re} f(z) d x d y \\
& =\operatorname{Re} \iint_{\varepsilon_{\rho}} f(z) d x d y=\frac{1}{2}\left(\rho^{2}-\rho^{-2}\right) \int_{-1}^{1}\left(1-x^{2}\right)^{1 / 2} f(x) d x \\
& \geqq \iint_{\sigma_{s}} \operatorname{Re} f(z) d x d y=\operatorname{Re} \iint_{\sigma_{s}} f(z) d x d y=\pi s^{2} f(0) .
\end{aligned}
$$

Other packings of the ellipse $\varepsilon_{\rho}$ by circles lead to other inequalities for the middle term of (34). See also Davis [6], p. 28.

ExAMPle. Let $0<w<\pi / 2$ be fixed. The function $f(z)=e^{w z}$, $z=x+i y$, is real on the real axis, and $\operatorname{Re} f(z)=e^{w x} \cos w y \geqq 0$ for $z \in C_{r}$ with $r=\pi / 2 w$. We have $r>1$. Hence, for 


$$
0<w<\pi / 2, \frac{1}{\sqrt{1-\left(\frac{2 w}{\pi}\right)^{2}}} \geqq \frac{2 I_{1}(w)}{w} \geqq \sqrt{1-\left(\frac{2 w}{\pi}\right)^{2}} .
$$

Equality holds for $w=0$, and the 2nd inequality, of course, is obvious from the Maclaurin expansion of $I_{1}(w) / w$.

The identity (28) leads to a simple quadrature for inner products of the type $\iint_{B} f(z) \overline{g(z)} d x d y$ and which holds under certain regularity conditions.

Lemma. Let $\Delta>\rho^{3}>\rho>1$, and suppose that $g(z)$ is regular in $\varepsilon_{\Delta}$. Let

$$
g(z)=\sum_{n=0}^{\infty} b_{n} p_{n}^{*}(z)
$$

be the expansion of $g$ in Tschebyscheff polynomials of the second kind. Then, the related function

$$
h(z)=\sum_{n=0}^{\infty}\left(\overline{b_{n}} / c_{n, \rho}^{2}\right) p_{n}^{*}(z)
$$

is regular in $\varepsilon_{A / \rho} 2$, and for all $f(z)$ regular in $\bar{\varepsilon}_{\rho}$, we have

$$
\iint_{\varepsilon_{\rho}} f(z) \overline{g(z)} d x d y=\frac{2}{\pi} \int_{-1}^{1}\left(1-x^{2}\right)^{1 / 2} h(x) f(x) d x .
$$

Proof. Note that $\varepsilon_{p} \subset \varepsilon_{4 \rho^{2}} \subset \varepsilon_{\rho^{3}} \subset \varepsilon_{4}$. Since $g(z)$ is regular in $\varepsilon_{4}$, we have

$$
\limsup _{n \rightarrow \infty}\left|b_{n}\right|^{1 / n} \leqq \frac{\rho}{\Delta}
$$

Since

$$
\lim _{n \rightarrow \infty}\left(\frac{1}{c_{n, \rho}^{2}}\right)^{1 / n}=\rho^{2}
$$

it follows that

$$
\limsup _{n \rightarrow \infty}\left|\frac{\overline{b_{n}}}{c_{n, \rho}^{2}}\right|^{1 / n} \leqq \frac{\rho}{\Delta} \cdot \rho^{2}=\frac{\rho}{\Delta / \rho^{2}} .
$$

Therefore $h(z)$ is regular in $\varepsilon_{A / \rho^{2}}$, the series (36) converging absolutely and uniformly in closed subsets of $\varepsilon_{1 / \rho^{2}}$.

Now we have

$$
\begin{aligned}
\iint_{\varepsilon_{\rho}} f(z) \overline{g(z)} d x d y & =\sum_{n=0}^{\infty} \overline{b_{n}} \iint_{\varepsilon_{\rho}} f(z) \overline{p_{n}^{*}(z)} d x d y \\
& =\sum_{n=0}^{\infty} \overline{b_{n}} c_{n, \rho} \iint_{\varepsilon_{\rho}} f(z) \overline{U_{n}(z)} d x d y .
\end{aligned}
$$


On the other hand,

$$
\begin{aligned}
\frac{2}{\pi} \int_{-1}^{+1} \sqrt{1-x^{2}} h(x) f(x) d x & =\frac{2}{\pi} \int_{-1}^{1} \sqrt{1-x^{2}} f(x) \sum_{n=0}^{\infty}\left(\overline{b_{n}} / c_{n, \rho}^{2}\right) p_{n}^{*}(x) d x \\
& =\sum_{n=0}^{\infty} \frac{\overline{b_{n}}}{c_{n, \rho}^{2}} \frac{2}{\pi} \int_{-1}^{1} \sqrt{1-x^{2}} f(x) p_{n}^{*}(x) d x \\
& =\sum_{n=0}^{\infty} \frac{\overline{b_{n}}}{c_{n, \rho}} \frac{2}{\pi} \int_{-1}^{1} \sqrt{1-x^{2}} f(x) U_{n}(x) d x
\end{aligned}
$$

Applying (28) to the last integral there is obtained

$$
\frac{2}{\pi} \int_{-1}^{+1} \sqrt{1-x^{2}} h(x) f(x) d x=\sum_{n=0}^{\infty} \overline{b_{n}} c_{n, \rho} \iint_{\varepsilon_{\rho}} f(z) \bar{U}_{n}(z) d x d y .
$$

Comparing (41) with (43) we obtain (37).

The relevant identities and convergence theorems for the Tschebyscheff polynomials $U_{n}(x)$ can be found in Szegö [9], p. 59 (4.1.7), p. 238, (9.1.4.).

If we define a linear transformation $T_{\rho}$ by means of

$$
T_{\rho}(g)=h(z)=\sum_{n=0}^{\infty} c_{n, \rho}^{2} \overline{b_{n}} p_{n}^{*}(z),
$$

then we can write (37) in the form

$$
\iint_{\varepsilon_{p}} f(z) \overline{g(z)} d x d y=\frac{2}{\pi} \int_{-1}^{+1} \sqrt{1-x^{2}} f(x) T \rho(g) d x .
$$

LEMma. Let $f(z)$ be regular in $\bar{\varepsilon}_{\rho}$ and let $g(z)$ be regular in $\varepsilon_{\Delta}$ where $\Delta>\rho^{3}>\rho>1$. Then,

$$
\iint_{\varepsilon_{\rho}} f(z) \overline{g(z)} d x d y=\frac{4}{\pi\left(\rho^{2}-\rho^{-2}\right)} \iint_{\varepsilon_{\rho}} f(z) T_{\rho}(g(z)) d x d y .
$$

Proof. Since $f(z)$ is regular in $\bar{\varepsilon}_{\rho}$ and since $T_{\rho}(g)$ is regular in $\varepsilon_{A / \rho^{2}}$, the product $f(z) T_{\rho}(g(z))$ is also regular in $\bar{\varepsilon}_{\rho}$. Hence, by (19) (with the $f(z)$ of this equation set equal to the present $f(z) T_{\mathrm{\rho}}(g(z)$ ),

(47) $\frac{2}{\pi} \int_{-1}^{+1} \sqrt{1-x^{2}} f(x) T_{\rho}(g(x)) d x=\frac{4}{\pi\left(\rho^{2}-\rho^{-2}\right)} \iint_{\varepsilon_{\rho}} f(z) T_{\rho}(g(z)) d x d y$.

Combining (45) with (47) we obtain (46).

We can now obtain the following simple quadrature.

THEOREM. Let $C_{n}:\left|z-z_{n}\right|<r_{n}, \quad n=1,2, \cdots$ be a complete packing of the ellipse $\varepsilon_{\rho}$. Let $g(z)$ be regular in $\varepsilon_{\Delta}$, where $\Delta>\rho^{3}>$ $\rho>1$. Then, for all $f$ that is regular in $\overline{\varepsilon_{\rho}}$, 


$$
\iint_{\varepsilon_{p}} f(z) \overline{g(z)} d x d y=\sum_{k=1}^{\infty} a_{k} f\left(z_{k}\right)
$$

where

$$
a_{k}=\frac{4}{\rho^{2}-\rho^{-2}} r_{k}^{2}\left(T_{\rho}(g(z))\right)_{z=z_{k}} .
$$

Proof. Under the above conditions, (46) holds.

Now write $\iint_{\varepsilon_{\rho}} f(z) T_{\rho}(g(z)) d x d y=\sum_{k=1}^{\infty} \iint_{\sigma_{k}} f(z) T_{\rho}(g) d x d y$ and apply the 2nd Lemma of $\S 2$.

This representation should be contrasted with that given in (14). The higher derivatives are no longer present.

5. The use of lunes. If $B$ is selected as the area common to two circles we may obtain a simple quadrature formula for another class of analytic functions.

Let $B$ designate the common part of the two circles

$$
|z-\sigma i|^{2}=1+\sigma^{2} \text { and }|z+\sigma i|^{2}=1+\sigma^{2} ; \sigma>0, i=\sqrt{-1} .
$$

These circles both pass through $z= \pm 1$ and their centers are at $z=$ $\sigma i$ and $z=-\sigma i$ respectively.

THEOREM. Let $C_{n}$ : $\left|z-z_{n}\right|<r_{n}, n=1,2, \cdots$ be a complete packing of the lune $B$. If $f(z)$ is regular in $\bar{B}$ and has zeros at $z=+1$ and $z=-1$, then,

$$
\int_{-1}^{+1} f(x) d x=\frac{\pi}{\sigma} \sum_{k=1}^{\infty} \frac{z_{k}^{2}+\sigma^{2}}{1-z_{k}^{2}} r_{k}^{2} f\left(z_{k}\right) \text {. }
$$

Proof. We have already established (see Davis [6]) that if $g(z)$ is regular in $\bar{B}$,

$$
\iint_{B} g(z) d x d y=\sigma \int_{-1}^{+1} g(x) \frac{1-x^{2}}{\sigma^{2}+x^{2}} d x .
$$

In view of the above conditions on $f(z)$, the function

$$
g(z)=\frac{f(z)\left(z^{2}+\sigma^{2}\right)}{1-z^{2}}
$$

will be regular in $\bar{B}$. Hence,

$$
\sigma^{-1} \iint_{B} \frac{f(z)\left(z^{2}+\sigma^{2}\right)}{1-z^{2}} d x d y=\int_{-1}^{+1} f(x) d x .
$$

The simple quadrature (50) now follows by writing $\iint_{B} g(z) d x d y=$ 
$\sum_{n=1}^{\infty} \iint_{\sigma_{n}} g(z) d x d y$

6. Final remarks. In (18) and in (50), we have seen how simplequadratures (with complex abscissas) may be found for $\int_{-1}^{1}\left(1-x^{2}\right)^{1 / 2} f(x) d x$ and for $\int_{-1}^{1}\left(1-x^{2}\right) f(x) d x$. Regarding these integrals as linear functionals on $f$, we can pose the following question. For what ilnear functionals $L$ is there a simple representation of the form

$$
L(f)=\sum_{n=1}^{\infty} a_{n} f\left(z_{n}\right)
$$

which is valid for every function $f$ of a space $F$ of functions that are regular in a fixed region $B$ ? If an expansion of type (53) were demanded for all linear functionals in $F^{*}$, then we are inquiring whether or not the point functionals $L_{n}(f)=f\left(z_{n}\right)$ form a basis for the dual space $F^{*}$, convergence being taken in the weak* sense of (53). Information on either of these problems, derived from the theory of normed linear spaces or from the theory of functions, would be welcome.

\section{BIBLIOGRAPHY}

1. R. P. Boas, Entire functions, New York, 1954.

2. T. Carleman, Sur les series $\Sigma A_{\nu} /\left(z-\alpha_{\nu}\right)$, Comptes Rendus, 174 (1922), 588-591.

3. P. J. Davis, On simple quadratures, Proc. Amer. Math. Soc. 4 (1953), 127-136.

4. P. J. Davis and J. L. Walsh, On representations and extensions of bounded linear functionals defined on classes of analytic functions, Trans. Amer. Math. Soc. 76 (1954), 190-206.

5. P. J. Davis, Packing inequalities for circles, Michigan Journal of Math. 10 (1963), $25-31$.

6. Triangle formulas in the complex plane, Math. of Computation, 18 (1964), 569-577.

7. - Interpolation and approximation, New York, 1963.

8. D. Pompeiu, Opera mathematica, 1959.

9. G. Szegö, Orthogonal polynomials, New York, 1939.

10. G. N. Watson, A Treatise on the theory of Bessel functions, 2nd Ed., 1952, London and New York.

11. J. Wermer, Uniform approximation and maximal ideal spaces, Bull. Amer. Math. Soc. 68 (1962), 298-305.

12. O. Wesler, An infinite packing theorem for spheres, Proc. Amer. Math. Soc. 11 (1960), 324-326.

13. J. Wolff, Sur les series $\Sigma A_{\nu} /\left(z-a_{\nu}\right)$, Comptes Rendus, 173 (1921), 1056-1057.

BROWN UNIVERSITY 


\section{PACIFIC JOURNAL OF MATHEMATICS}

\section{EDITORS}

\author{
H. Samelson \\ Stanford University \\ Stanford, California \\ R. M. Blumenthal \\ University of Washington \\ Seattle, Washington 98105
}

\author{
J. Dugundu \\ University of Southern California \\ Los Angeles, California 90007 \\ *Richard Arens \\ University of California \\ Los Angeles, California 90024
}

\section{ASSOCIATE EDITORS}
E. F. BeCKENBACH
B. H. NeUMANN
F. WOLF
K. YosidA

\section{SUPPORTING INSTITUTIONS}

\author{
UNIVERSITY OF BRITISH COLUMBIA \\ CALIFORNIA INSTITUTE OF TECHNOLOGY \\ UNIVERSITY OF CALIFORNIA \\ MONTANA STATE UNIVERSITY \\ UNIVERSITY OF NEVADA \\ NEW MEXICO STATE UNIVERSITY \\ OREGON STATE UNIVERSITY \\ UNIVERSITY OF OREGON \\ OSAKA UNIVERSITY \\ UNIVERSITY OF SOUTHERN CALIFORNIA
}

\author{
STANFORD UNIVERSITY \\ UNIVERSITY OF TOKYO \\ UNIVERSITY OF UTAH \\ WASHINGTON STATE UNIVERSITY \\ UNIVERSITY OF WASHINGTON \\ * * * * \\ AMERICAN MATHEMATICAL SOCIETY \\ CALIFORNIA RESEARCH CORPORATION \\ SPACE TECHNOLOGY LABORATORIES \\ NAVAL ORDNANCE TEST STATION
}

Mathematical papers intended for publication in the Pacific Journal of Mathematics should by typewritten (double spaced). The first paragraph or two must be capable of being used separately as a synopsis of the entire paper. It should not contain references to the bibliography. No separate author's resumé is required. Manuscripts may be sent to any one of the four editors. All other communications to the editors should be addressed to the managing editor, Richard Arens, at the University of California, Los Angeles, California 90024.

50 reprints per author of each article are furnished free of charge; additional copies may be obtained at cost in multiples of 50 .

The Pacific Journal of Mathematics is published quarterly, in March, June, September, and December. Effective with Volume 13 the price per volume (4 numbers) is $\$ 18.00$; single issues, $\$ 5.00$. Special price for current issues to individual faculty members of supporting institutions and to individual members of the American Mathematical Society: $\$ 8.00$ per volume; single issues $\$ 2.50$. Back numbers are available.

Subscriptions, orders for back numbers, and changes of address should be sent to Pacific Journal of Mathematics, 103 Highland Boulevard, Berkeley 8, California.

Printed at Kokusai Bunken Insatsusha (International Academic Printing Co., Ltd.), No. 6, 2-chome, Fujimi-cho, Chiyoda-ku, Tokyo, Japan.

PUBLISHED BY PACIFIC JOURNAL OF MATHEMATICS, A NON-PROFIT CORPORATION

The Supporting Institutions listed above contribute to the cost of publication of this Journal, but they are not owners or publishers and have no responsibility for its content or policies.

* Basil Gordon, Acting Managing Editor until February 1, 1966. 


\section{Pacific Journal of Mathematics}

\section{Vol. 15, No. $3 \quad$ November, 1965}

David R. Arterburn and Robert James Whitley, Projections in the space of

bounded linear operators .................................

Robert McCallum Blumenthal, Joram Lindenstrauss and Robert Ralph Phelps,

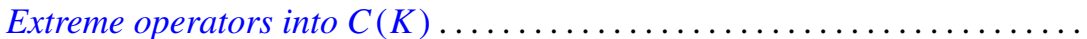

L. Carlitz, A note on multiple exponential sums ................... 757

Joseph A. Cima, A nonnormal Blaschke-quotient .................... 767

Paul Civin and Bertram Yood, Lie and Jordan structures in Banach algebras . . . 775

Luther Elic Claborn, Dedekind domains: Overrings and semi-prime

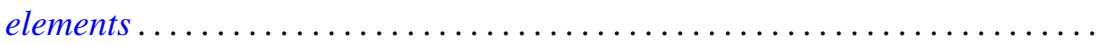

799

Luther Elic Claborn, Note generalizing a result of Samuel's .............. 805

George Bernard Dantzig, E. Eisenberg and Richard Warren Cottle, Symmetric

dual nonlinear programs ................................... 809

Philip J. Davis, Simple quadratures in the complex plane ............... 813

Edward Richard Fadell, On a coincidence theorem of F. B. Fuller ............ 825

Delbert Ray Fulkerson and Oliver Gross, Incidence matrices and interval

graphs ........................................ 835

Larry Charles Grove, Tensor products over $H^{*}$-algebras ..................

Deborah Tepper Haimo, $L^{2}$ expansions in terms of generalized heat polynomials

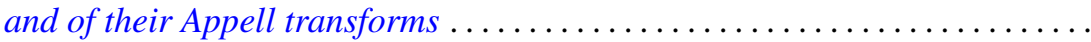

I. Martin (Irving) Isaacs and Donald Steven Passman, A chardcterization of groups in terms of the degrees of their characters ..........

Donald Gordon James, Integral invariants for vectors over local fields........ 905

Fred Krakowski, A remark on the lemma of Gauss ................... 917

Marvin David Marcus and H. Minc, A subdeterminant inequality ........... 921

Kevin Mor McCrimmon, Norms and noncommutative Jordan algebras ........ 925

Donald Earl Myers, Topologies for Laplace transform spaces ............... 957

Olav Njstad, On some classes of nearly open sets .................... 961

Milton Philip Olson, A characterization of conditional probability ........... 971

Barbara Osofsky, A counter-example to a lemma of Skornjakov .............. 985

Sidney Charles Port, Ratio limit theorems for Markov chains ............... 989

George A. Reid, A generalisation of $W^{*}$-algebras ...................... 1019

Robert Wells Ritchie, Classes of recursive functions based on Ackermann's

function ........................................... 1027

Thomas Lawrence Sherman, Properties of solutions of $n$th order linear

differential equations ........................................ 1045

Ernst Snapper, Inflation and deflation for all dimensions . .............. 1061

Kondagunta Sundaresan, On the strict and uniform convexity of certain Banach

spaces............................................. 1083

Frank J. Wagner, Maximal convex filters in a locally convex space .......... 1087

Joseph Albert Wolf, Translation-invariant function algebras on compact 